\title{
Planificación urbana mall-deada: La territorialización del mall Lincoln Plaza, Moravia, Costa Rica
}

\author{
Andrés Jiménez Corrales
}

Artículo

Afiliación: Universidad de Costa Rica, Costa Rica.

E-mail: andres.jimenezcorrales@ucr.ac.cr

Recibido: 30 de septiembre del 2019

Aceptado: 29 de abril del 2020
Andrés Jiménez Corrales

Geógrafo. Docente e investigador en el Instituto de Investigaciones Sociales, Escuela de Geografía y Departamento de Salud Ambiental, Universidad de Costa Rica.

\begin{abstract}
Resumen
La planificación urbana es interpretada, frecuentemente, como un instrumento técnicoobjetivo. Este hecho esconde los intereses políticos reales que impulsan la formulación, la concreción y la modificación de instrumentos de planificación territorial. A través del caso de estudio de la territorialización del mall Lincoln Plaza, el artículo expone argumentos para debatir la premisa presentada. Para ello, utiliza como metodología la revisión documental de actas municipales, noticias periodísticas, bibliografía y entrevistas. Los resultados demuestran la creación de apoyos público-privados para la construcción del mall Lincoln Plaza, logrado a través de una transformación del instrumento de planificación territorial local e influenciado por intereses particulares y privados.
\end{abstract}

Palabras clave: Lincoln Plaza; Municipalidad de Moravia; planificación urbana; territorialización; urbanismo neoliberal.

Urban planning as a territorial transformation policy: The case of Lincoln Plaza mall territorialization, Moravia, Costa Rica

\begin{abstract}
:
Urban planning is often interpreted as a technical-objective instrument. This fact hides the real political interests that drive the formulation, concretion and modification of territorial planning instruments. Through the case study of Lincoln Plaza mall territorialization, the article sets out arguments to discuss the premise presented. To do this, it uses as a methodology the review of documents, such as municipal records, journalistic news, bibliography and interviews. Results demonstrate the creation of public-private support for Lincoln Plaza mall building, achieved through a transformation of the local territorial planning instrument and influenced by particular and private interests.
\end{abstract}

Keywords: Lincoln Plaza; Municipality of Moravia; urban planning; territorialization; neoliberal urbanism. 


\section{Introducción}

I titular de un diario digital del 10 de noviembre del año 2012, anunciaba: "Miles de ticos visitan Lincoln Plaza y ocasionan caos vial" (Contreras, 2012). Esta noticia se escribió el día que abrió sus puertas el mall Lincoln Plaza, un centro comercial que se suma a esta tipología de comercio en Costa Rica. El título, por simple que parezca, reúne dos aspectos característicos del modelo de ciudad predominante en el país y, en general, en Latinoamérica:

1. Los malls representan espacios predilectos para estar y recrearse en la ciudad.

2. El automóvil figura como medio de transporte privilegiado para movilizarse en la ciudad.

Los malls surgen en el escenario urbano estadounidense en el año 1956, se extienden regionalmente durante la década de 1960 (Salcedo y De Simone, 2013), y aparecen por primera vez en Costa Rica en el año 1993 (Jiménez, 2017). En cada país su surgimiento tuvo características particulares, dependientes de las trayectorias históricas, culturales, políticas y económicas de su contexto. Salcedo y De Simone (2013) mencionan que el éxito de la diseminación de los malls se debe a ciertas características que los diferencian de otras arquitecturas comerciales, por ejemplo, fue un espacio que se ajustó al proceso de suburbanización y la automovilización de la sociedad urbana, particularidad compartida en los distintos países. Además, el mall presenta un modelo de implementación territorial centralizado y eficiente, que logra maximizar las ganancias de inversores y comerciantes (Salcedo y De Simone, 2013).

Lo anterior ayuda a explicar el comportamiento narrado en el titular periodístico, contextualizando la relevancia que tienen estos espacios dentro de la sociedad urbana.

Los cambios en la producción de ciudad, incluyendo la aparición de los malls, reflejan modificaciones en la estructura social. En este contexto se pone en tensión la función de lo público y privado dentro de la planificación urbana; considerando que los malls están lejos de representar espacios públicos que surgen de un acuerdo político o cultural de la ciudadanía, sino que tiene como fin vender bienes o servicios, por ende, tienen un interés privado en su producción (Salcedo y De Simone, 2012).

En este trabajo se presenta y se discute en torno al proceso político que permitió la territorialización del mall Lincoln Plaza. Para lo anterior, se presentarán una serie de acontecimientos experimentados para la aparición de este centro comercial. A partir del caso de estudio, se posiciona una crítica a la planificación urbana considerada como un simple instrumento técnico. Este objetivo se logra a través de una reconstrucción de las discusiones, las acciones y los acuerdos dados en torno a la llegada del Lincoln Plaza, para esto se realiza una triangulación de datos de cuatro fuentes: 1) revisión documental de actas del expediente municipal sobre el caso, normativa y prensa escrita; 2) entrevistas semi-estructuradas: a) al Director de Urbanismo del Instituto Nacional de Vivienda y Urbanismo (INVU); y b) a un miembro de la Junta de Educación del Colegio Lincoln; y 3) sondeos con vecinos que residen en los alrededores del Lincoln Plaza'. El periodo de estudio comprendió los años 2007 y 2008.

\section{Territorialización en tiempos neoliberales: breves notas teóricas}

$1 \quad$ Estas labores se realizaron durante el año 2015, en el marco de la elaboración de la tesis de Licenciatura en Geografía del autor.
La territorialización, en este trabajo, se entiende como el proceso mediante el cual actores ejercen un control sobre un espacio, a través de la creación de una estrategia espacial que les permita obtener, influir o controlar recursos y personas (Sack en Haesbaert, 2011). La territorialización refiere a configuraciones específicas de actores que condensan una constelación de acuerdos o desacuerdos. Con estas acciones se crea una lógica territorial que ejerce un poder que moldea dinámicas locales, regionales o globales, pero a la vez, pugna por la apropiación y el control de un espacio (Haesbaert, 2011 y Raffestin, 2011). Este es un proceso que puede concretar, o no, territorios, por lo que es relevante entender su constitución histórica. 
El marco normativo de un Estado, y en específico los instrumentos de planificación urbana, representan territorios simbólicos que generan ciertas condiciones para la territorialización de actores diversos. La planificación urbano-territorial se convierte, bajo este lente, en un campo de referencia territorial que reúne dos particularidades: 1) su oficialización representa la condensación de una serie de acuerdos y negociaciones entre actores, 2) su transformación o derogación es dependiente de un cambio en las relaciones de poder o aparición de otros actores en el territorio. Este tipo de planificación se encuentra estrechamente enlazada a un sistema de poder que emite un plano de ideas, acciones y proyecciones que producen territorios, modificando relaciones socioespaciales.

La planificación urbana es dependiente de un marco de ideas (ideologías) que impulsa la concreción de un "orden" que pretende reproducir un proyecto político-económico, por ejemplo, el neoliberalismo (Carmona, 2012). Estas acciones de gestión producen intervenciones territoriales que modifican territorios previos, representando un acto violento que borra, parcial o totalmente, una existencia anterior para producir algo nuevo y diferente (Swyngedouw, 2011).

En tiempos neoliberales, la territorialización de la planificación urbana potencia ciertas transformaciones en los modos de gestión de las ciudades. Por ejemplo, los gobiernos locales se han ajustado a estos nuevos patrones a partir del impulso de la competencia, la promoción local y las adaptaciones regulatorias para atraer empleo o inversiones (Brenner y Theodore, 2017). Lo anterior supone una adecuación en los gobiernos locales, incluida la planificación urbana, para favorecer la territorialización de ciertos actores en la ciudad. Estos son elementos que reconfiguran las relaciones entre actores (institucionales y económicos) y modifican lógicas regulatorias redistributivas por competitivas (Theodore, Peck y Brenner, 2009).

El neoliberalismo promueve experimentos distintos en los modos de gobernanza de las ciudades. Estos ensayos tienen como fin principal la movilización del espacio de la ciudad para originar un desarrollo urbano puesto al servicio del mercado y de las prácticas de consumo de las clases medias y altas (Brenner y Theodore, 2017). La territorialización de nuevos actores ocasiona modificaciones en las realidades socioespaciales de un lugar, modelando disparidades territoriales que ponen de relieve la profundización de desigualdades socio-económicas. Con estas prácticas, ciertas áreas de la ciudad se producen como exclusivas y excluyentes en distintas dimensiones y niveles.

Bajo este lente, se va a analizar el caso de la territorialización del mall Lincoln Plaza, prestando atención en los acomodos institucionales que se tuvieron que realizar para su concreción. A través de la exposición se brindan elementos para realizar una crítica a la planificación urbana como instrumento técnico neutral utilizado como estrategia de poder para tener legitimación social y ocultar su parcialidad.

\section{El mall Lincoln Plaza como caso de estudio}

El mall Lincoln Plaza se localiza en el barrio Los Colegios, distrito San Vicente, cantón Moravia (Figura 1). Durante la primera mitad del siglo XX, este territorio se caracterizó por la presencia de grandes extensiones de café, propiedad de la familia Challe 2 . A partir de la década de 1940, inicia la urbanización de los cafetales de esta familia y de otros propietarios. En el año 1952, el señor André Challe, dona parte de sus propiedades para la construcción de centros educativos privados que sirvieran como nodos de articulación de la urbanización (Umaña, 1945; Ríos, et al., 1994; Enríquez, 1998). Un año después, el Colegio Lincoln se establece en este lugar (Lincoln School,

2 El beneficio de la familia Challe era uno de los principales procesadores y exportadores de café de Costa Rica, sólo superado por los beneficios Tournon y Lindo Bros (Enríquez, 1998). 2015; Arias, 2000).

En los albores de los años 2000, la asamblea general de asociados del Colegio Lincoln, toma la decisión de trasladar su institución a otro lugar (Arias, 2000; R. Mora, comunicado personal, 2015). En el año 2005, se hace efectiva la venta de la propiedad del Colegio a la empresa Portafolio Inmobiliario Sociedad Anónima (PINMSA) (R. Mora, comunicado personal, 2015); y en el año 2007, se inaugura las nuevas instalaciones 
3 Según el plan regulador, en su artículo 14 , establece que los tipos de usos permitidos dentro de esta zonificación son: "Todos aquellos usos que conforman un colegio (aulas, Gimnasios, soda, canchas multiuso, oficinas administrativas del colegio, pasillos, instalaciones sanitarias, laboratorios, talleres y similares, bibliotecas, enfermería y parqueos)...." (Municipalidad de Moravia, 2000). del Colegio Lincoln en otra localidad (Lincoln School, 2015). Es a partir de ese año, que la empresa PINMSA puede hacer uso efectivo de la propiedad del antiguo colegio.

\section{Territorio previo como "obstáculo"}

En el año 2007, PINMSA inicia los trámites administrativos en la Municipalidad de Moravia para obtener los permisos de construcción para el nuevo mall. La empresa, a través de este procedimiento, se entera que su proyecto tiene un impedimento por la zonificación de uso de la tierra establecida en el plan regulador de Moravia. La propiedad de PINMSA se encuentra bajo la zonificación "educacional privada"3, normado en el Artículo 14 del Plan Regulador de Moravia, lo que prohíbe el establecimiento de otro tipo de uso de la tierra. Se comprueba que esta es una zonificación restrictiva, que tiene sentido por el territorio precedente, donde el Colegio Lincoln representaba un actor de poder en la localidad.

El Plan Regulador, normado en la Ley de Planificación Urbana (N. 4242 del 15 de noviembre de 1968), es el instrumento oficial de planificación territorial local que

"...define en un conjunto de planos, mapas, reglamentos y cualquier otro documento, gráfica o suplemento, la política de desarrollo y los planos para la distribución de la población, usos de la tierra, vías de circulación, servicios públicos, facilidades comunales y construcciones; conservación y rehabilitación de áreas urbanas". (Municipalidad de Moravia, 2000)

Para el caso del cantón Moravia, el plan regulador fue oficializado por el Concejo Municipal el día 24 de mayo del 2000.

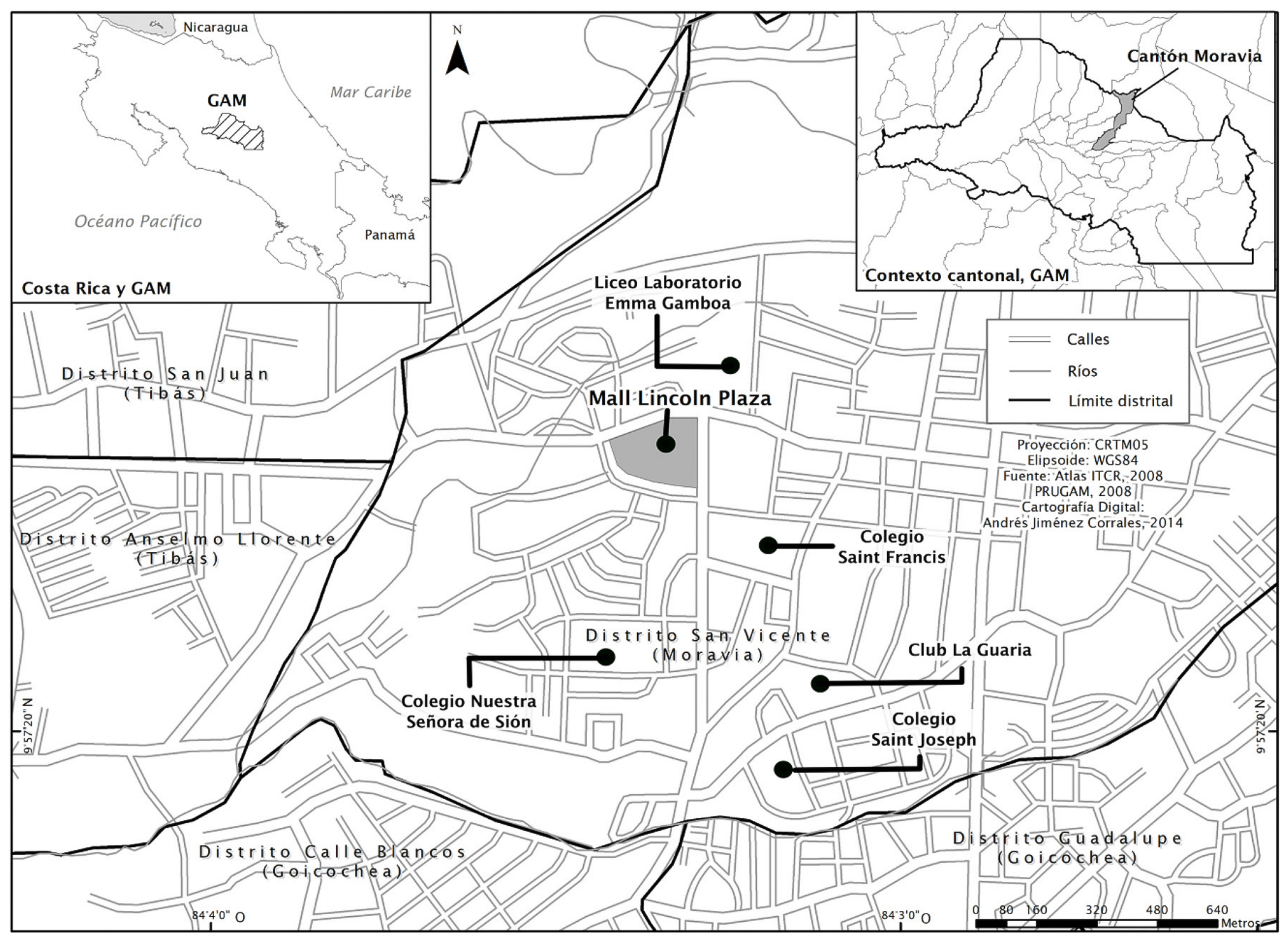

Figura 1. Localización del mall Lincoln Plaza en 
El uso de la tierra proyectado por la empresa era considerado bajo las condiciones normativas de ese momento, como un "uso no conforme". Este tipo de uso es aquel "... que no se ajusta a la zonificación propuesta” (Municipalidad de Moravia, 2000, Artículo 1), por lo que no se podía emitir permisos de construcción 0 de funcionamiento ${ }^{4}$. El proceder institucional seguido para resolver este "obstáculo", es el contenido de las siguientes páginas.

\section{Borrando territorios previos}

En el expediente municipal que reúne la documentación relacionada al caso de la construcción del mall, se ubicó una carta fechada del día 02 de octubre del 2007, donde el apoderado generalísimo de PINMSA, el señor Andrew Paul Vickers, se dirige a la Dirección de Planificación de la Municipalidad de Moravia. En esta misiva se expresan las intenciones de la empresa de construir un centro comercial en el terreno que ocupaba el Colegio Lincoln. El señor Vickers apunta que conoce los impedimentos normativos para la construcción de una infraestructura comercial en esa propiedad. Ante esa circunstancia, solicitó una revisión del instrumento de planificación, específicamente su zonificación, para lo cual se ampara en el artículo $39^{5}$ de dicho reglamento, solicitando que se emita un "uso experimental" para el desarrollo de su proyecto (Municipalidad de Moravia, s.f., folios 1 y 2 ).

El caso se redirigió para su valoración a la Comisión INVU-Municipalidad. Esta instancia se reunió entre los días 02 y 08 de octubre del 2007, donde se recomendó al Alcalde Edgar Vargas Jiménez ${ }^{6}$ elevar al Concejo Municipal el caso, para que oficialmente se convoque a la misma instancia para el análisis respectivo. La Comisión expresó que el obstáculo se puede resolver mediante una interpretación de la normativa vigente 0 , mediante una modificación del plan regulador (Municipalidad de Moravia, s.f., folio 5).

El 22 de octubre del 2007, se realizó la Sesión Ordinaria \#22 del Concejo Municipal de Moravia, donde se discutió el contenido de la carta y la resolución emitida por la Comisión. Como resultado de la discusión, se toma el Acuerdo \#1051, donde se estipula convocar a la Comisión INVU-Municipalidad para analizar el caso. Esta instancia le ordena a la Comisión proponer una solución posible en caso de que no se pueda aplicar el Artículo 39 del Reglamento del Plan Regulador, ya que este proyecto "...es de gran importancia para el cantón..." (Municipalidad de Moravia, Sin fecha, folio 6).

$4 \quad$ El Artículo 4 del reglamento del plan regulador de Moravia establece que, en un uso no conforme, se prohíbe dar permisos para construcción, remodelación o ampliación (Municipalidad de Moravia, 2000).

\section{El artículo 39 del plan regulador de} Moravia instaura los mecanismos para la modificación y actualización de este instrumento. Dentro de ello, se abre la posibilidad de otorgar "usos experimentales" para aquellos usos no contemplados dentro de la reglamentación, pero sustentados en criterios técnicos por parte del INVU y la Municipalidad (Municipalidad de Moravia, 2000). 2006-2010

Alcalde de Moravia durante el periodo

$7 \quad$ En el Reglamento del Plan Regulado de Moravia se define en el artículo 1 el uso condicional como: "... aquel uso que puede darse en una zona, previa autorización especial tanto de la Municipalidad, Ministerio de Salud, Dirección de Urbanismo del INVU, fijándole restricciones y requisitos especiales técnicamente definidos, adicionales a los establecidos para los usos conformes".
El 2 de noviembre del 2007, el Alcalde Edgar Vargas Jiménez convocó oficialmente a la Comisión INVU-Municipalidad. La comisión estuvo integrada por las siguientes personas: Roberto Morales Delgado (asesor legal), Iván Arce Vargas (director de Ingeniería y Operaciones) y Marvin Valverde Tenorio (planificador municipal), por parte de la Municipalidad de Moravia; y Leonel Rosales (director de Urbanismo), de parte del Instituto Nacional de Vivienda y Urbanismo (INVU) (Municipalidad de Moravia, s.f., folio 7 y 8$)$.

En un mes y tres días después, el 5 de diciembre del 2007, la Comisión INVUMunicipalidad proclamó una resolución bajo el Informe \#10-2007, donde concluyó lo siguiente: 1) Es prioridad de la municipalidad la protección de la Zona Educacional Privada, pero es necesario crear un uso condicional ${ }^{7}$ que permita eliminar la inflexión establecida; 2) El fin de la Zona Educacional Privada ha cambiado; 3) De seguir con la zonificación actual se estaría inhibiendo a los titulares de la propiedad privada de su uso productivo; y 4) Son ilegítimas las limitaciones a la propiedad. Ante esta situación recomendaron: a) Crear un uso condicional; b) Solicitar estudios específicos a la empresa interesada; y c) Adicionar al artículo 14 del reglamento del plan regulador un tercer punto que establezca el uso condicional (Municipalidad de Moravia, sin fecha, folios $8,9,10$ y 11).

Esta resolución se revisó en la sesión del Concejo Municipal del día 12 de diciembre del 2007 (Sesión Extraordinaria \#40). En esta instancia, sin mayor discusión, se aprobaron las recomendaciones emitidas. Luego de darse este consentimiento, se inició con los trámites administrativos para convocar a una Audiencia Pública ${ }^{8}$, en la cual las personas de Moravia, bajo lo establecido en la normativa, tenían la oportunidad de discutir y recomendar cambios a la propuesta de adición al artículo 14 del Plan Regulador 
(Municipalidad de Moravia, s.f., folios 14, 15 y 16). Hasta ese día, la población de Moravia no tenía conocimiento sobre el proyecto, ya que toda la discusión previa se había congregado en las esferas institucionales sin ninguna consulta pública.

Los acuerdos logrados a este momento se basaron en un interés por crear las condiciones normativas para la llegada del centro comercial. En el expediente analizado no fue posible encontrar pruebas que demuestren que la decisión fue tomada considerando algún tipo de estudio técnico. Con esto se muestra un tipo de accionar parcializado y condicionado por un actor de poder que pretende llegar al territorio. Este hecho resalta el interés de las autoridades locales, en conjunción con los nacionales, para facilitar la territorialización del mall. Lo anterior representa una expresión del empresarialismo urbano del gobierno local (Salinas, 2014; Di Virgilio y Guevara, 2015).

\section{Un requisito, nada más}

El Concejo Municipal de Moravia acogió las recomendaciones manifestadas por la Comisión INVU-Municipalidad, por lo que se le dio continuidad al procedimiento administrativo establecido en la Ley N. 4240 de Planificación Urbana (del 15 de noviembre del 1968) y en el Manual de Procedimientos para la Redacción y Elaboración de Planes Reguladores del INVU. El siguiente paso fue convocar una audiencia pública, donde se expondría la propuesta de cambio al plan regulador a las personas habitantes del cantón. Lo anterior tenía dos objetivos: 1. Dar a conocer el proyecto del mall y 2. Someter a "juicio" de esta población la propuesta de modificación del plan regulador.

Antes de la audiencia pública, las personas del lugar desconocían lo que se estaba fraguando, brotando dudas sobre lo que se iba a establecer en el terreno del antiguo Colegio Lincoln. Esto creó expectativas diversas entre la población, especulando que en esa propiedad se iba a establecer una universidad privada, un centro de salud, una biblioteca o un centro comercial ${ }^{9}$.

La modificación de la normativa municipal atrasó los planes iniciales de la empresa para la inauguración del mall, quienes pretendían abrir las puertas del Lincoln en el año 2008, según lo expresó este actor a la prensa escrita (Camacho, 2009). La realidad provocó que los planes iniciales se demoraran, a tal punto que, la empresa para el año citado no había podido obtener los permisos de construcción necesarios para el inicio de las obras.

La Audiencia Pública se oficializó con la publicación de un anuncio en el periódico La Prensa Libre y La Gaceta, el día 30 de enero del 2008. La Audiencia fue pactada para el día 25 de febrero del 2008, a las 11 a.m., en el Salón de Sesiones del Concejo Municipal de Moravia (Municipalidad de Moravia, s.f., folio 14). Resalta el día de la semana y la hora en la que se decide convocar este encuentro, que, por razones de jornada laboral ordinaria, iba a dificultar la asistencia de una mayoría. Esto pudo provocar que personas que estaban interesadas en asistir, no lo pudieran hacer, debido a que se encontraban en su horario de trabajo. Un proceder de este tipo, se interpreta como una estrategia de producción territorial por parte del actor institucional, que puede tener un interés de favorecer la territorialización del mall.

$8 \quad$ La audiencia pública forma parte de los requisitos que se tienen que cumplir para desarrollar un cambio en un plan regulador. Se ahondará sobre ello más adelante.

$9 \quad$ Obtenido en las entrevistas realizadas a los actores locales. Para el caso del centro comercial, se especulaba que se iba a construir uno de la marca "Multiplaza" (es una cadena de centros comerciales que pertenece al grupo empresarial salvadoreño Grupo Roble).
El 25 de febrero del 2008 se realizó la audiencia pública, contando con una participación total de 51 personas (Municipalidad de Moravia, s.f., folios 45, 46 y 47).

Este encuentro fue la primera vez que las autoridades municipales presentan a los actores locales el proyecto de adición al artículo 14 del Reglamento del Plan Regulador.

En la Audiencia, las personas que pudieron asistir, formularon, de manera escrita u oral, una serie de interrogantes y dudas sobre lo propuesto, pero, también, presentaron propuestas de modificación. Estos elementos no pudieron ser abordados por las autoridades municipales durante el encuentro. La Municipalidad contestó de manera escrita cada uno de los aspectos señalados, en un periodo de un mes y 13 días después de efectuada la Audiencia Pública (Municipalidad de Moravia, s.f., folios 48 al 71).

En resumen, en la Tabla 1 se presenta una categorización de las interrogantes y las dudas planteadas durante la Audiencia. Con esto se quiere brindar una visión de conjunto que permita entender lo comentado, discutido y cuestionado durante el encuentro. 
Tabla 1. Categorización de las interrogantes, dudas y propuestas presentadas en la audiencia pública del 25 de febrero del 2008.

Fuente: Municipalidad de Moravia, s.f., folios 31 al 71. Elaboración propia.

\begin{tabular}{|c|c|c|}
\hline Tipo & Explicación & Contenido \\
\hline $\begin{array}{l}\text { De } \\
\text { procedimiento }\end{array}$ & $\begin{array}{l}\text { Abarca dudas } \\
\text { e interrogantes } \\
\text { acerca de cómo fue } \\
\text { que se llevó a cabo } \\
\text { la propuesta de } \\
\text { adición al artículo } \\
14 \text { del reglamento } \\
\text { del plan regulador. }\end{array}$ & $\begin{array}{l}\text { Algunos de los aspectos que se cuestionan son: } \\
\text { Cuál es la justificación para otorgar el uso } \\
\text { de suelo condicional, cuáles fueron los } \\
\text { parámetros utilizados para proponer esto y } \\
\text { de qué forma se resolvió hacerlo.2. Cómo } \\
\text { se compone y cuál es la naturaleza de la } \\
\text { Comisión INVU-Municipalidad. } \\
\text { De dónde nace la propuesta de adición: } \\
\text { concejo municipal, alcaldía o comisión. } \\
\text { La propuesta pretende adaptar el plan } \\
\text { regulador a un tipo de proyecto. } \\
\text { Se reclama sobre las desigualdades en la } \\
\text { forma de proceder del actor institucional, } \\
\text { ya que en algunos casos se hace todo } \\
\text { este procedimiento, mientras que en otros } \\
\text { casos solo se les dice que no. } \\
\text { Seponeencuestionamientolaconformación } \\
\text { de la Comisión INVU-Municipalidad. Se } \\
\text { expresa que esta instancia debería de } \\
\text { incluir a personas con alto conocimiento de } \\
\text { la situación cantonal. } \\
\text { Se cuestionan las razones por las cuales } \\
\text { solo se modifica el artículo } 14 \text { del plan } \\
\text { regulador, señalando que existen otras } \\
\text { inconsistencias dentro de las zonificaciones } \\
\text { del distrito San Vicente. }\end{array}$ \\
\hline De contenido & $\begin{array}{l}\text { Agrupa las dudas } \\
\text { e interrogantes } \\
\text { relacionadas a } \\
\text { los contenidos de } \\
\text { la propuesta de } \\
\text { adición al artículo } \\
14 \text { del reglamento } \\
\text { del plan regulador. }\end{array}$ & $\begin{array}{l}\text { Los elementos que se ubican dentro de esta } \\
\text { categoría son: } \\
\text { De qué manera fueron consideradas } \\
\text { otras zonas del cantón para realizar } \\
\text { modificaciones a la zonificación normada, } \\
\text { al igual que se está haciendo para el caso } \\
\text { del mall. } \\
\text { Qué es lo que se entiende por una } \\
\text { desactualización del Plan Regulador. } \\
\text { Será que el proyecto presentado se está } \\
\text { realizando por el interés de auspiciar un } \\
\text { proyecto comercial. } \\
\text { A raíz de que elementos el actor } \\
\text { institucional presenta como justificante para } \\
\text { la aprobación de la adición las actuales } \\
\text { tendencias de desarrollo para la zona. Por } \\
\text { lo que los actores locales cuestionan lo } \\
\text { siguiente: a) qué es lo que se entiende por } \\
\text { las actuales tendencias de desarrollo; y b) } \\
\text { quién define qué es desarrollo. }\end{array}$ \\
\hline De contexto & $\begin{array}{l}\text { Agrupa una } \\
\text { serie de dudas } \\
\text { e interrogantes } \\
\text { sobre las posibles } \\
\text { consecuencias que } \\
\text { puede ocasionar el } \\
\text { establecimiento del } \\
\text { mall en Moravia. }\end{array}$ & $\begin{array}{l}\text { Los aspectos que se ubican dentro de esta } \\
\text { categoría son: } \\
\text { - Qué se hará para mantener la seguridad e } \\
\text { integridad de los barrios circundantes. } \\
\text { - Cómo será tratado los temas de medio } \\
\text { ambiente, el tránsito y la congestión vial. } \\
\text { - Cómo será afectado el "hábitat residencial". } \\
\text { - Por otra parte, una de las asistentes a la } \\
\text { audiencia lo que reclama es la necesidad } \\
\text { que tiene su comunidad, Platanares, de } \\
\text { tener salones comunales e iglesias. }\end{array}$ \\
\hline
\end{tabular}


El principal reclamo de parte de las personas asistentes a la Audiencia fue el procedimiento del gobierno local para la creación de la propuesta de adición al artículo 14 del plan regulador de Moravia. Además, las personas protestan sobre el actuar parcializado de la Municipalidad para beneficiar a una empresa (ver en Tabla 1, categoría "De procedimiento"). Esto es una prueba que permite cuestionar las formas dominantes de planificación urbano-territorial, las cuales se realizan de manera jerarquizada y bajo relaciones de poder que benefician a actores privados dominantes. Este proceder se puede interpretar como "empresarialismo urbano", el cual tiende a generar las condiciones institucionales para que las empresas se territorialicen (Harvey, 2007; Brenner, 2017; Franquesa, 2007; Di Virgilio y Guevara, 2015; Salinas, 2014).

Se comprobó que las personas que asistieron a la Audiencia desconocían el funcionamiento, el contenido y los procedimientos de modificación del Plan Regulador (ver Tabla 1 categoría "De contenido"). Este hecho permite que el actor institucional se apropie y controle para su beneficio los instrumentos de planificación, limitando la concreción de una planificación territorial participativa. Lo anterior reduce la participación ciudadana a una validación de la propuesta, excluyendo parcialmente a las personas de los procesos de modificación de normativa. Todo esto permite cuestionar la existencia del Derecho a la Ciudad (Harvey, 2013) que tienen las personas del lugar, donde parece más bien que, las acciones territoriales en la ciudad están al servicio de la acumulación del capital.

Estos hechos demuestran la materialización de un campo de fuerzas (Souza en Haesbaert, 2011, p. 69) que favorece el establecimiento en el territorio de un actor empresarial por medio de un acomodo de las condiciones normativas para sus objetivos. También se determinó que existió una disputa simbólica por el territorio bajo relaciones de poder desiguales. Las personas presentes en la Audiencia ingresaron al escenario de negociación supeditadas a reglas pre-establecidas tiempo atrás por el gobierno local, quien a su vez, representó la autoridad que define qué se acepta y qué se rechaza. Por lo que este actor es juez y parte en la decisión.

\section{Ocultando decisiones parcializadas}

Los cuestionamientos y las dudas emitidas por las personas que asistieron a la Audiencia, fueron aplacadas contestando que la propuesta de cambio parcial del instrumento de planificación urbana no respondía a un caso en específico o proyecto determinado. La justificación que utilizan para explicar su accionar es que, de mantenerse la actual zonificación, se estaría inhibiendo a los titulares de la propiedad privada de un uso productivo (Municipalidad de Moravia, s.f., folios 31 al 71). Dichos argumentos pueden constituirse en una posible contradicción, ya que se pudo comprobar en el expediente del caso que la propuesta de modificación se inició por petición de la empresa interesada en la construcción del mall Lincoln Plaza. Esto se convierte en una estrategia política utilizada por el gobierno local para ocultar un proceso parcializado como uno objetivo y sin un actor específico de por medio. Raffestin (2011) explica que los actores utilizan estrategias comunicacionales como un medio para modificar, apropiarse y dominar territorios.

La estrategia que se utilizó para la modificación del artículo 14 del plan regulador de Moravia, estuvo dentro de los límites de acción del territorio municipal, lo que definió el espacio de relación, condicionando las "reglas del juego" (Raffestin, 2011). Este proceder se defendió apelando que labores de esta índole ocupan de criterios técnicos y especializados para efectuarse (Municipalidad de Moravia, s.f., folio 75). Este argumento erige un límite simbólico entre el actor institucional, "propietario del conocimiento", y las personas del lugar, "receptores pasivos del conocimiento".

Lo planteado es contradictorio con las evidencias encontradas. Al revisar el expediente municipal del caso, no se comprobó que las autoridades utilizaran criterios técnicos para la elaboración de su propuesta. El gobierno local acopló su discurso para beneficiar la territorialización de la empresa. Esto representa una característica del modo de gestión local en tiempos neoliberales, donde se crean las condiciones normativas para la atracción de inversiones al territorio, las cuales están lejos de generar beneficios extensivos en la ciudad (Harvey, 2007; Salinas, 2014). 
La Municipalidad se concentró sólo en responder las interrogantes planteadas en la audiencia, los demás fueron desechados. La Comisión INVU-Municipalidad envió una carta al Concejo Municipal el día 9 de abril del $2008^{10}$, donde concluye que en la Audiencia Pública no se aportaron argumentos técnicos o legales para realizar alguna modificación a la propuesta, y se recomienda enviarla a la Dirección de Urbanismo del INVU para su aprobación (Municipalidad de Moravia, s.f., folio 75).

\section{Los obstáculos fueron vencidos}

En la Sesión Ordinaria \#102 del 16 de abril del 2008, el Concejo Municipal, bajo el Acuerdo \#1290, decide enviar la propuesta para su aprobación final a la Dirección de Urbanismo del INVU. Con esta potestad, el Alcalde Edgar Vargas Jiménez, envía la propuesta de adición al señor Leonel Rosales, Director de Urbanismo del INVU, con el fin de que dicha institución realice un dictamen al respecto (Municipalidad de Moravia, s.f., folios 76 al 82).

El 23 de mayo del 2008 el señor Leonel Rosales Maroto, envió una carta al Alcalde Edgar Vargas Jiménez, aprobando la adición al artículo 14 del Reglamento del Plan Regulador de Moravia. Señala que el cambio de la normativa entrará en vigencia cuando se publique en el periódico oficial La Gaceta (Municipalidad de Moravia, s.f., folios 96 al 102).

La resolución del INVU es revisada en el Concejo Municipal en la Sesión Ordinaria $\# 109$, del 2 de junio del 2008, para su aprobación final. En ella se justifica que se siguió el debido proceso demandado por la normativa vigente. Así, se acoge el Acuerdo \#1360 donde se aprueba la adición al artículo 14, en firme y definitivamente (Municipalidad de Moravia, s.f., folios 103 al 107). El cambio de la normativa se vuelve oficial el 11 de junio del 2008, con su publicación en el periódico La Gaceta (Foto 1).

Figura 2. Publicación de la adición al artículo 14 del Reglamento del Plan Regulador de Moravia, en La Gaceta 112.

Fuente: Municipalidad de Moravia, s.f., folios 166 al 168. Foto: Andrés Jiménez Corrales, julio 2015.

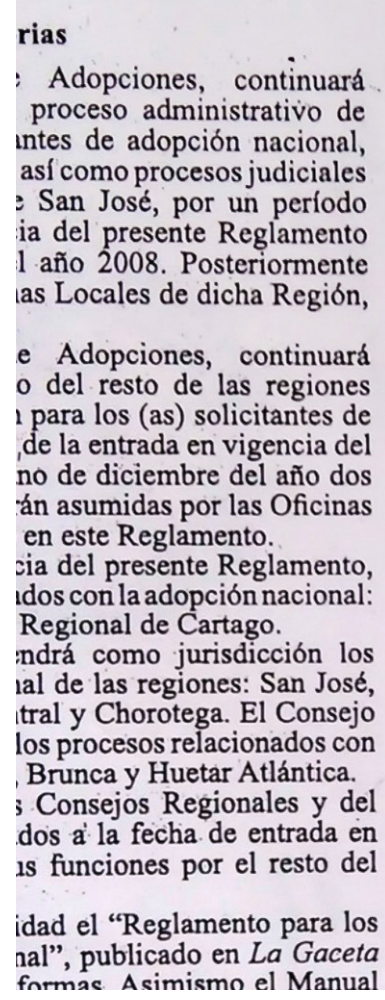

rias

- Adopciones, continuará proceso administrativo de intes de adopcion nacional, - San José, por un periodo San José, por un periodo ia del presente Reglamento as Locales de dicha Región,

e Adopciones, continuará o del resto de las regiones I para los (as) solicitantes de de la entrada en vigencia del no de diciembre del año dos án asumidas por las Oficinas en este Reglamento. ia del presente Reglamento, idos con la adopción nacional: Regional de Cartago. ndrá como jurisdicción los tal de las regiones: San José, tral y Chorotega. El Consejo los procesos relacionados con Brunca y Huetar Atlantica. ;. Consejos Regionales y del dos a la fecha de entrada en
is funciones por el resto del idad el "Reglamento para los aal", publicado en La Gaceta
fnrmac A simismn el Manua

Artículo $\mathrm{N}^{\circ} 7^{\circ}$ - Se aprueba el presente reglamento según artículo V), 9), de la sesión $\mathrm{N}^{\circ} 32-2007$ celebrada el 11 de setiembre del 2007. odrigo Fernández Cedeño, Jefe. -1 vez.-(O. C. No 10123).-C18940.-(50796).

MUNICIPALIDADES MUNICIPALIDAD DE MORAVIA

ADICIÓN AL ARTÍCULO 14 DEL REGLAMENTO AL PLAN REGULADOR DE MORAVIA 2008

Acuerdo $\mathrm{N}^{\circ} 1360$, sesión ordinaria $\mathrm{N}^{\circ} 109$ de fecha 2 de junio de

Habiéndose cumplido con todo el debido proceso, derecho de defensa, soberanía popular, participacion ciudadana, especialidad, legalidad y constando aprobación de la Direccion General de Urbanismo del Instituto . párrafo final que dirá:

3. Uso condicional. En esta zona se podrá otorgar uso condicional habitacional, comercial o servicios, siempre y cuando el comportamiento urbano predomlica y privada), sea apta para el tipo de desarrollo que se pretende. Las solicitudes de uso serán resueltas de derar los titulares de Planificación por unicien de Urbanismo del INVU.

3.1. La Comisión encargada de otorgar un uso condicional tiene potestad para solicitar los estudios téenicos que sean necesarios y establecer requisitos especiales tecnicamente definidos,

\section{Planificación urbana mall-deada: una interpretación}

La territorialización del mall Lincoln Plaza fue posible a través de una alianza entre el sector público y privado que potenció el acomodo de las condiciones normativas para su construcción. A lo largo de la exposición se evidenció la estrategia utilizada por los actores dominantes (institucional y empresarial) para controlar el espacio simbólico de un instrumento de planificación urbana y lograr sus objetivos. Dicha intervención permitió la territorialización del mall, desencadenando nuevas dinámicas urbanas en el territorio. 
En el caso de estudio, se observó como el instrumento oficial de planificación urbana fue mall-deado de acuerdo a los intereses de un actor privado dominante. Por su parte, el gobierno local ejerció un rol de facilitador y de promotor para la llegada del centro comercial al territorio. A través de estos elementos, se interpreta la planificación urbana como un instrumento político influenciado por las configuraciones de poder coyunturales. Bajo tiempos neoliberales, estas lógicas regulatorias tienden a promover la maximización de la acumulación de capital de ciertos actores privados, afectando la creación de acciones redistributivas que beneficien a la mayoría de la población (Theodore, Peck y Brenner, 2009). El geógrafo Yves Lacoste (1975), afirma que:

"en nuestros días la proliferación de discursos que versan sobre la ordenación del territorio, en términos de armonía, de búsqueda de mejores equilibrios, sirve sobre todo para ocultar las medidas que permiten a las empresas capitalistas... aumentar sus beneficios." (p. 15)

El acuerdo señalado hizo posible el arribo del Lincoln Plaza y delineó un futuro territorial. Un proyecto urbano de esta magnitud transformó las dinámicas locales y regionales, favoreciendo al mercado y a un consumo exclusivo de una clase (Brenner y Theodore, 2017). Esto genera una exclusión para otros grupos de personas que no pueden acceder a los bienes y servicios ofrecidos en este territorio.

El mall, como espacio post-público (Salcedo, 2003), ha ido ganando un lugar central dentro de un modelo de ciudad segregado (Salinas, 2014). Esto hace cuestionar la relación entre lo público y privado en la producción territorial de la ciudad; además permite criticar las capacidades reales del Estado, en todos sus niveles, para producir espacios públicos en la ciudad. El mall, simbólicamente, representa una narrativa legitimadora (Franquesa, 2007) y una realidad espacial que introduce dinámicas y prácticas socio-espaciales que moldean la ciudad. Este tipo de centro comercial se ha convertido en un "objeto del deseo" que valida su llegada al territorio y permite la creación o modificación de instrumentos técnico-legales para su territorialización. Estos acontecimientos llevan a debatir ¿Para quiénes se está construyendo ciudad?

\section{Referencias bibliográficas}

Arias, S. (2000, 24 de septiembre). Colegio Lincoln deja Moravia. El Financiero. En línea http://wvw.elfinancierocr.com/ef_archivo/2000/septiembre/24/negocios4.html

Brenner, N. y Nick, T. (2017). Las ciudades y las geografías del neoliberalismo realmente existente. En: Sevilla, A. (ed.). 2017. Neil Brenner. Teoría urbana crítica y políticas de escala. Icaria.

Camacho, A. (2009, 2 de agosto). Plaza Lincoln alista planos y permisos. El Financiero. En línea http://wvw.elfinancierocr.com/ef_archivo/2009/agosto/02/negocios2032963. $\mathrm{html}$

Carmona, J. (2016). Planificación urbana capitalista: Apuntes para una reflexión crítica a la producción social del espacio. Revista Brasileña Estudios Urbanos Regionales. V. 18, n. 3.

Costa Rica. (1968). Ley nº 4240 de Planificación Urbana del 15 de noviembre de 1968.

Contreras, L. (2012, 10 de noviembre). Miles de ticos visitan Lincoln Plaza y ocasionan caos vial. CRHoy.com. En línea: http://www.crhoy.com/archivo/miles-de-ticosvisitan-lincoln-plaza-en-su-inauguracion-y-ocasionan-caos-vial/nacionales/

DiVirgilio, M. y Guevara, T. (2015). Gentrificación liderada porel Estado yempresarialismo urbano en la Ciudad Autónoma de Buenos Aires. En: Delgadillo, V., Díaz, I., y L. Salinas. (2015). Perspectivas del estudio de la gentrificación en México y América Latina. Instituto de Geografía, UNAM.

Jiménez, A. (2017). "Mall"-deando la ciudad: 24 años de territorialización de los malls en Costa Rica. RevistArquis. Vol. 7, n². Universidad de Costa Rica.

Haesbaert, R. (2011). El mito de la desterritorialización. Del "fin de los territorios" a la multiterritorialidad. Traducción Marcelo Canossa. Siglo XXI.

Harvey, D. (2007). Espacios del capital. Hacia una geografía crítica. Akal. 
Harvey, D. (2013). Ciudades rebeldes. Del derecho de la ciudad a la revolución urbana. Akal.

Franquesa, J. (2007). Vaciar y llenar, o lógica espacial de la neoliberalización. Revista Reis. N 118 , pp. 123-150.

Katz, C. (2012). Interpretaciones de la crisis. En: Estrada, Jairo (Coord.) La crisis capitalista mundial y América Latina: lecturas de economía política. CLACSO.

Lacoste, Y. (1975). La geografía: un arma para la guerra. Anagrama.

Lincoln School. (2015). 70th Aniversary Lincoln Schooll. Excellence since 1945. En línea: http://www.lincoln.ed.cr/en/

Municipalidad de Moravia. (2000). Plan regulador.

Municipalidad de Moravia. (Sin fecha). ExpedienteAdición al artículo 14. Plan Regulador. Departamento de Urbanismo.

Raffestin, C. (2011). Por una geografía del poder. Traducción y notas Yanga Villagómez Velázquez. El Colegio de Michoacán.

Ríos, D., León, H., Rivera, A., Sanabria, M., Vargas, G. y Zeledón, P. (1994). El cantón de Moravia desde la perspectiva histórico-geográfica. 1828-1970. Monografía. Seminario de Graduación para optar al grado de Licenciatura en Geografía e Historia. Universidad de Costa Rica.

Salcedo, R. (2003). Lo local, lo global y el mall: la lógica de la exclusión y la interdependencia. Revista de Geografía Norte Grande. № 30.

Salcedo, R., y, De Simone, L. (2012). Los malls en Chile. 30 años. Cámara Chilena de Centros Comerciales. Chile.

Salcedo, R., y, De Simone, L. (2013). Una crítica estática para un espacio en constante renovación: el caso del mall en Chile. Revista Atenea. Vol. 507.

Salinas, L. (2014). Transformaciones urbanas en el contexto neoliberal. La colonia Condesa en Ciudad de México: hacia un proceso de gentrificación. Cuadernos de Investigación Urbanística. N. 93.

Swyngedouw, E. (2011). ¡La naturaleza no existe! La sostenibilidad como síntoma de una planificación despolitizada. Revista URBAN N. 01.

Theodore, N., Peck, J., y Brenner, N. (2009). Urbanismo neoliberal: la ciudad y el imperio de los mercados. Revista Temas Sociales. N 66. Chile.

Umaña, L. (1945). Estudio del cantón Moravia. [Tesis para optar al grado de Profesor de Enseñanza Primaria. Universidad de Costa Rica.] 